\title{
Genomic Segments RNA1 and RNA2 of Prunus necrotic ringspot virus Codetermine Viral Pathogenicity to Adapt to Alternating Natural Prunus Hosts
}

\author{
Hongguang Cui, ${ }^{1,2} \mathrm{Ni}$ Hong, ${ }^{3}$ Guoping Wang, ${ }^{1}$ and Aiming Wang ${ }^{2}$ \\ ${ }^{1}$ National Key Laboratory of Agromicrobiology, Huazhong Agricultural University, Wuhan, Hubei 430070, People's Republic \\ of China; ${ }^{2}$ Southern Crop Protection and Food Research Centre, Agriculture and Agri-Food Canada, 1391 Sandford St., \\ London, ON, N5V 4T3, Canada; ${ }^{3}$ College of Plant Science and Technology, Hubei Crop Disease Monitoring and Safety \\ Control Key Laboratory, Huazhong Agricultural University, Wuhan, Hubei 430070, People's Republic of China
}

Submitted 3 December 2012. Accepted 19 January 2013.

\begin{abstract}
Prunus necrotic ringspot virus (PNRSV) affects Prunus fruit production worldwide. To date, numerous PNRSV isolates with diverse pathological properties have been documented. To study the pathogenicity of PNRSV, which directly or indirectly determines the economic losses of infected fruit trees, we have recently sequenced the complete genome of peach isolate Pch12 and cherry isolate Chr3, belonging to the pathogenically aggressive PV32 group and mild PV96 group, respectively. Here, we constructed the Chr3- and Pch12-derived full-length cDNA clones that were infectious in the experimental host cucumber and their respective natural Prunus hosts. Pch12-derived clones induced much more severe symptoms than Chr3 in cucumber, and the pathogenicity discrepancy between $\mathrm{Chr} 3$ and Pch12 was associated with virus accumulation. By reassortment of genomic segments, swapping of partial genomic segments, and site-directed mutagenesis, we identified the $3^{\prime}$ terminal nucleotide sequence (1C region) in RNA1 and amino acid $K$ at residue 279 in RNA2-encoded $P 2$ as the severe virulence determinants in Pch12. Gain-of-function experiments demonstrated that both the $1 \mathrm{C}$ region and K279 of Pch12 were required for severe virulence and high levels of viral accumulation. Our results suggest that PNRSV RNA1 and RNA2 codetermine viral pathogenicity to adapt to alternating natural Prunus hosts, likely through mediating viral accumulation.
\end{abstract}

Prunus necrotic ringspot virus (PNRSV) is a viral pathogen that occurs worldwide and infects many stone fruit such as peach, cherry, plum, apricot, almond, and nectarine as well as ornamentals, including rose (Pallas et al. 2012). PNRSV is transmitted by pollen and seed or via infected vegetative propagation materials such as budwood and rootstock (Fiore et al. 2008; Oliver et al. 2009). PNRSV is a species of the genus Ilarvirus in the family Bromoviridae of plant RNA viruses

Corresponding author: A. Wang; Telephone: +1 5194571470 ext. 313; Fax: +1 519 4573997; E-mail: aiming.wang@agr.gc.ca

* The $\boldsymbol{e}$-Xtra logo stands for "electronic extra" and indicates that two supplementary figures and one supplementary table are published online.

(C) 2013 The American Phytopathological Society
(Fauquet et al. 2005). Viruses in the family Bromoviridae have a tripartite RNA genome of plus-strand polarity (Fauquet et al. 2005). RNA1 and RNA2 are monocistronic and encode replicase proteins P1 and P2, respectively (Francki 1985). RNA3 is bicistronic and has two open reading frames (ORF) (SánchezNavarro and Pallás 1997). The 5'-proximal ORF encodes the movement protein (MP), and the $3^{\prime}$-proximal ORF codes for the coat protein $(\mathrm{CP})$, which is translated via a subgenomic messenger RNA, termed RNA4 (Fauquet et al. 2005; Francki 1985).

To date, numerous PNRSV isolates have been reported from all over the world. Based on their MP or CP sequences, PNRSV isolates could be classified into four major phylogroups (i.e., PV32, PV96, PE5, and CH30) (Aparicio and Pallás 2002; Aparicio et al. 1999; Cui et al. 2012a; Fiore et al. 2008; Glasa et al. 2002; Hammond 2003; Vasková et al. 2000). Depending on the isolate of the virus and host species, PNRSV infections can be asymptomatic or latent, or induce a variety of symptoms such as mosaic, ringspot, chlorosis, necrosis, and leaf deformation (Fiore et al. 2008; Oliver et al. 2009). Symptom severity directly or indirectly determines the economic losses caused by the virus through deteriorating tree vigor and reducing fruit yield and quality; therefore, the pathological properties of PNRSV naturally become a focus of research. Previous results indicated that there is no significant correlation between the different phylogroups and virulence severity (Aparicio and Pallás 2002; Aparicio et al. 1999; Cui et al. 2012a; Fiore et al. 2008; Glasa et al. 2002; Hammond 2003; Vasková et al. 2000). However, it has also been reported that mild isolates of the $\mathrm{CH} 9$ serotype, including isolates $\mathrm{CH} 61$ and $\mathrm{CH} 39$, cluster into the PV96 group whereas rugose isolates such as $\mathrm{CH} 9, \mathrm{CH} 38$, and $\mathrm{CH} 59$ cluster into a subgroup in the PV32 group (Aparicio et al. 1999; Hammond and Crosslin 1998). Thus, severe PNRSV isolates are likely to cluster into the PV32 group whereas mild isolates tend to belong to the PV96 group (Hammond 2003). These contrasting observations may be attributed to the following reasons. First, previous studies mainly used the RNA3-encoded MP or CP sequences. In those studies, RNA1 and RNA2 were seldom sequenced either fully or partially, making it impossible to assess their roles in pathogenicity and to classify PNRSV isolates using the whole genome sequence. Second, PNRSV symptoms have mainly been evaluated based on observations on adult trees in the field. Because mixed infections with other viruses or viroids (i.e., Prune dwarf virus, Apple 
chlorotic leaf spot virus, and Peach latent mosaic viroid) have been commonly found in stone fruit trees (Herranz et al. 2005; Peiró et al. 2012; Saade et al. 2000; Sánchez-Navarro et al. 2005), the possibility that the observed symptoms are caused by mixed infections of PNSRV and other viruses rather than PNRSV alone is not excluded. Finally, it has been well established that, as a result of genetic diversity introduced during viral replication, an infected virus may generate a virus population that subsequently differentiates into several distinct populations following systemic invasion of different host species (Jridi et al. 2006). This is particularly the case for virally infected adult fruit trees. It remains unknown whether, in those published reports, the observed symptoms are caused by a single PNRSV isolate or by distinct isolates evolved from the same virus from the primary infection after years of systemic infection.

To study the pathological properties of PNRSV, we have recently surveyed its incidence and symptoms in cherry and peach trees in the Niagara fruit belt in Ontario, Canada (Cui et al. 2012a). We have also partially sequenced a number of $\mathrm{Ca}$ nadian PNRSV isolates and determined the complete genome of two PNRSV isolates: Chr3 (PV96-type) and Pch12 (PV32type) (Cui et al. 2012a and b). Here, we report on the construction of the infectious cDNA clones of Chr3 and Pch12. Pathogenicity tests on the natural and experimental hosts showed that the symptoms induced by Pch12 were much more severe than those induced by Chr3. By exchanging genomic segments, swapping partial genomic segments, and site-directed mutagenesis, the pathogenicity determinants were identified.

\section{RESULTS}

Chr3- and Pch12-derived full-length cDNA clones are infectious in their natural and experimental hosts but exhibit different pathological properties.

The full-length cDNAs of genomic segments RNA1, RNA2, and RNA3 of PNRSV isolates Chr3 and Pch12 were successfully cloned into plasmid pCass4-Rz (Fig. 1). The full-length cDNAs were placed between the double-35S promoter and the ribozyme sequence cassette $(\mathrm{Rz})$. Transcription started from the nucleotide $\mathrm{G}$ for all three genomic segments RNA1, RNA2, and RNA3 (Fig. 1), allowing the precise production of their respective authentic viral $5^{\prime}$ ends. At the $3^{\prime}$ ends, transcription of RNA1, RNA2, and RNA3 cDNAs would generate an additional 29, 29, and 17 nucleotides, respectively, beyond the natural $3^{\prime}$ AGC sequence due to the presence of a self-cleaving ribozyme.

To test infectivity of the Chr3- and Pch12-derived clones, cucumber cotyledons ('Straight Eight') were co-infiltrated with a mixture of agrobacterial cultures harboring three T-DNA constructs containing the corresponding full-length cDNAs of genomic RNA1, RNA2, and RNA3. At 18 days postinoculation (dpi), plants were examined for symptoms induced by the virus derived from these cDNA clones (Table 1). Plants infiltrated with $\mathrm{Chr} 3$ clones showed yellowish and mild necrosis symptoms on the third and fourth true leaves of plants (Fig. 2A), whereas Pch12 clones apparently induced more severe symptoms in cucumber such as severe ringspot and necrosis on all leaves, including cotyledons, and very small stature (Fig.
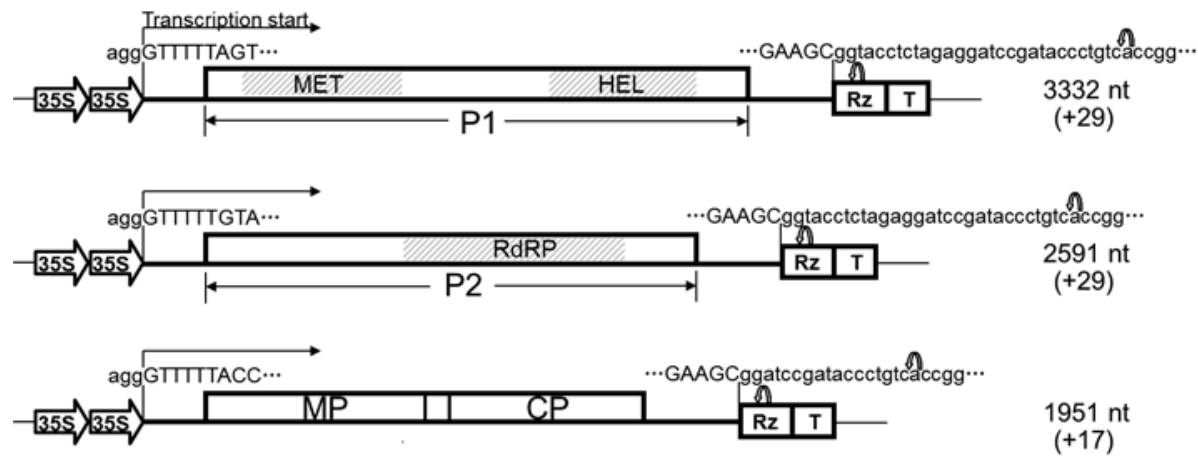

Fig. 1. Characteristics of T-DNA plasmids harboring genomic RNA1, RNA2, and RNA3 of Prunus necrotic ringspot virus (PNRSV) isolate Pch12 used for transient expression in plants. T-DNA constructs contain full-length cDNA copies of PNRSV genomic RNA1, RNA2, and RNA3. Single lines and open boxes represent noncoding and coding regions, respectively. Monocistronic RNA1 and -2 encoding the corresponding replicase proteins P1 and P2, and dicistronic RNA3 encoding 5'-proximal movement protein (MP) and 3'-proximal coat protein (CP), which are separated by a short intergenic region (IR) sequence. At the $5^{\prime}$ junction, nucleotide sequence of the double-35S promoter (indicated by lowercase) and the $5^{\prime}$ sequence of each genomic cDNA (indicated by uppercase) are shown. Domains for methyltransferase (MET), helicase (HEL), and RNA-dependent RNA polymerase (RdRp) are indicated. The transcription start site is indicated by a bent arrow. At the $3^{\prime}$ end of each construct, $3^{\prime}$ nucleotide sequence of each genomic cDNA is indicated by uppercase and the nonviral sequences (left after self-cleavage by the ribozyme) is indicated by lowercase. The self-cleavage site of ribozyme is indicated by a bent arrow. The length of wild-type genomic RNAs of PNRSV isolate Pch12 and the number of non-viral nucleotides left after self-cleavage by ribozyme (shown in bracket) are indicated.

Table 1. Summary of the infectivity and symptoms of Prunus necrotic ringspot virus isolates Chr3 and Pch12 in different hosts

\begin{tabular}{|c|c|c|c|c|}
\hline Host & Isolate & $\mathbf{d p i}^{\mathbf{a}}$ & Infectivity (\%) & Symptoms \\
\hline \multirow[t]{2}{*}{ Cucumber 'Straight Eight' } & Chr3 & 18 & 100 & Yellowish and mild necrosis symptoms on the third and fourth true leaves \\
\hline & Pch12 & $\ldots$ & 100 & Severe ringspot and necrosis on all leaves and very small stature \\
\hline \multirow[t]{2}{*}{ Cherry 'Bing' } & $\mathrm{Chr} 3$ & 18 & 100 & Irregularly shaped necrosis spots on newly emerging leaves and slightly smaller stature \\
\hline & Pch12 & $\ldots$ & 100 & $\begin{array}{l}\text { Dwarfism symptoms, necrosis on newly emerging leaves and the death of the young } \\
\text { shoot tip }\end{array}$ \\
\hline \multirow[t]{2}{*}{ Peach 'GF305' } & Chr3 & 14 & 0 & Not applicable \\
\hline & Pch12 & $\ldots$ & 25 & $\begin{array}{l}\text { Severe chlorotic ringspot symptoms on newly emerging leaves, which quickly became } \\
\text { necrotic and dropped off to form "shot holes" }\end{array}$ \\
\hline \multirow[t]{2}{*}{ Peach 'Loring' } & Chr3 & 20 & 0 & Not applicable \\
\hline & Pch12 & $\ldots$ & 37.5 & Mild mosaic symptoms on newly emerging leaves \\
\hline
\end{tabular}

${ }^{a}$ Days postinoculation. 

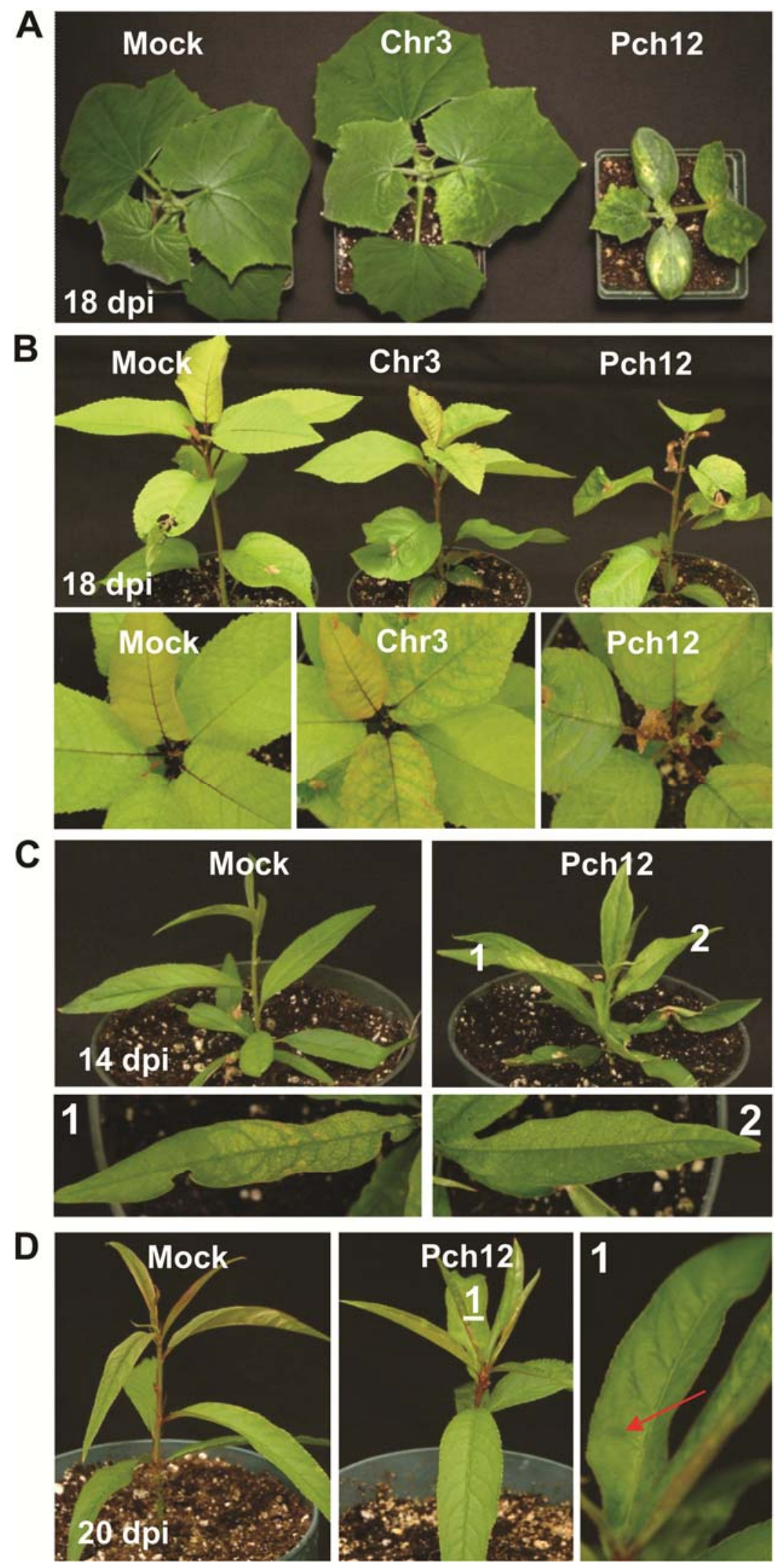

Fig. 2. Pathogenicity test of two Prunus necrotic ringspot virus isolates Chr3 and Pch12 in their experimental and natural hosts. A, Symptoms in Cucumis sativus 'Straight Eight'. At 18 days postinoculation (dpi), plants infiltrated with Chr3 clones showed mild necrosis symptoms on the third and fourth true leaves, and Pch12 clones induced severe ringspot and necrosis on all leaves, including cotyledons, and were very small in stature. B, Disease response in Prunus avium 'Bing'. At 18 dpi, Pch12 triggered severe top wilting and necrosis symptoms, and isolate Chr3 induced milder symptoms (e.g., irregularly shaped necrosis spots on new emerging leaves and slightly smaller stature). C, P. persica GF305 infected by Pch12 showed severe chlorotic ringspot symptoms, ring-shaped necrosis, and "shot holes" symptoms on newly emerging leaves at 14 dpi. Close views of marked leaves 1 and 2 are shown. D, Pch12 induced mild mosaic symptoms on the newly emerging leaves in P. persica 'Loring' seedlings at $20 \mathrm{dpi}$. 
2A). These symptoms were not evident in mock-treated plants (infiltrated with agrobacterial cells containing empty vectors) (Fig. 2A). Double-antibody sandwich enzyme-linked immunosorbent assays (DAS-ELISA) and reverse-transcription polymerase chain reaction (RT-PCR) confirmed the presence of the PNRSV virus in all the cucumber plants infiltrated with the Chr3 or Pch12 clones. These results suggest that the fulllength cDNA clones derived from PNRSV isolates Chr3 and Pch12 are infectious in cucumber plants but differ in virulence severity.

To further test whether these clones are also infectious in their natural hosts, three mixed full-length cDNA plasmids were biolistically introduced into peach ('Loring' or 'GF305') and cherry ('Bing') seedlings. Cherry plants inoculated with Pch12 showed dwarfism symptoms, necrosis on newly emerging leaves, and the death of the young shoot tip at 18 dpi (Fig. 2B; Table 1). In contrast, isolate Chr3 induced milder symptoms in all inoculated cherry plants, and the identified symptoms included irregularly shaped necrosis spots on new, emerging leaves and slightly smaller stature in comparison with mocktreated cherry seedlings (Fig. 2B). DAS-ELISA and RT-PCR confirmed that all of those cherry plants bombarded with Pch12- or Chr3-derived clones were infected by PNRSV.

In peach, $25 \%$ of 'GF305' seedlings inoculated with Pch 12 showed severe chlorotic ringspot symptoms on newly emerging leaves, which quickly became necrotic and dropped off to form "shot holes" at 14 dpi (Fig. 2C; Table 1). Approximately one-third of inoculated 'Loring' peach seedlings displayed mild mosaic symptoms on newly emerging leaves at $20 \mathrm{dpi}$ (Fig. 2D; Table 1). Along with growth of peach seedlings, the symptoms gradually disappeared. All peach seedlings initially showing symptoms were PNRSV positive by DAS-ELISA and RT-PCR. In contrast, no symptoms were discernible in any 'Loring' or 'GF305' peach seedlings bombarded with Chr3derived clones. No PNRSV infection was evident on either the newly emerging leaves or leaves bombarded with Chr3 cDNAs (data not shown). These data suggest that Chr3-derived clones are infectious in cherry (mild symptoms on systemic leaves) but are not able to infect peach, and Pch12-derived clones can infect both peach (showing mild or undetectable symptoms on systemic leaves) and cherry (with severe necrosis leading to the death of the shoot tip). These data are consistent with our recent findings that no severe symptoms were evident on the systemic leaves of the Chr3-infected cherry tree or those of the Pch12-infected peach tree (Cui et al. 2012a). Taken together, the above data suggest that the Chr3- and Pch12-derived fulllength cDNA clones are infectious in both experimental and natural hosts but possess different pathological properties, with Pch12 being more aggressive on all three tested plant species.

\section{The pathogenicity discrepancy between Chr3- and Pch12-derived full-length cDNA clones is associated with virus accumulation.}

To investigate the molecular mechanisms underlying the pathogenicity discrepancy of $\mathrm{Chr} 3$ and Pch12, cucumber was further used as the experimental host, for the following reasons. First, cucumber plants are much more obtainable than peach or cherry seedlings. Second, cucumber, showing 100\% susceptibility to both Chr3 and Pch12, is an efficient susceptible experimental host to PNRSV. Finally, Agrobacterium-mediated inoculation, which is highly efficient for cucumber but poor for peach and cherry, is much more convenient and economical than biolistic bombardment.

Symptom development on cucumber plants was closely monitored. Cucumber seedlings infected with Pch12 showed chlorotic spots on the first and second true leaves at approximately 6 to 8 dpi (Fig. 3A) and stunted growth and extreme leaf dis- tortion after approximately 12 to 14 dpi (Figs. 2A and 3A). In contrast, no detectable symptoms on Chr3-infected cucumber seedlings were evident until approximately 16 to 18 dpi (Figs. $2 \mathrm{~A}$ and $3 \mathrm{~A}$ ). After that, infected plants started to show mild necrosis and distortion symptoms on the newly developing leaves and smaller stature than mock-treated controls (Fig. 3A).

To examine whether pathogenicity divergence between $\mathrm{Chr} 3$ and Pch12 is associated with virus titer, the newly developing leaves of Chr3- and Pch12-infected seedlings were harvested at 8,18 , and $28 \mathrm{dpi}$, and subjected to real-time quantitative (q)PCR analyses to detect relative virus accumulation levels. It was found that the relative amount of the virus in Chr3-infected seedlings was much lower than that in Pch12-infected ones at all three time points (Fig. 3B). Thus, the pathogenicity discrepancy between Chr3 and Pch 12 is, indeed, associated with virus accumulation.

\section{RNA1 and RNA2 are responsible for pathogenicity of PNRSV.}

As illustrated above, Chr3 and Pch12 exhibited remarkable differences in pathogenicity on all three tested plant species (Figs. 2 and 3). To identify which of the genomic segments RNA1, RNA2, and RNA3 was attributed to the pathogenicity discrepancy, hybrid viruses were obtained by reassortment of RNA1-, RNA2-, or RNA3-derived full-length clones between $\mathrm{Chr} 3$ and Pch12. For the convenience of description, $\mathrm{C} 1, \mathrm{C} 2$, and $\mathrm{C} 3$ were designated for RNA1, RNA2, and RNA3 of the isolate Chr3, respectively, and P1, P2, and P3 for the three genomic segments of the isolate Pch12, respectively (Fig. 4A). The resulting reassorted viral clones $\mathrm{P} 1 \mathrm{C} 2 \mathrm{C} 3, \mathrm{C} 1 \mathrm{P} 2 \mathrm{P} 3, \mathrm{C} 1 \mathrm{P} 2 \mathrm{C} 3$, $\mathrm{P} 1 \mathrm{C} 2 \mathrm{P} 3, \mathrm{C} 1 \mathrm{C} 2 \mathrm{P} 3$, and $\mathrm{P} 1 \mathrm{P} 2 \mathrm{C} 3$ were agroinfiltrated into cucumber seedlings, and symptom development was monitored and recorded. At $8 \mathrm{dpi}$, the newly developing leaves of all agroinfiltrated seedlings were harvested for a DAS-ELISA test to estimate the virus accumulation level.

Reassorted viruses $\mathrm{C} 1 \mathrm{C} 2 \mathrm{P} 3$ and $\mathrm{P} 1 \mathrm{P} 2 \mathrm{C} 3$, produced by exchanging genomic segment RNA3 between Chr3 and Pch12, induced symptoms very similar to their respective wild-type viruses Chr3 and Pch12, suggesting that genomic segment RNA3 did not play a critical role in determining the pathogenicity difference between $\mathrm{Chr} 3$ and Pch12. In contrast, hybrid viruses $\mathrm{C} 1 \mathrm{P} 2 \mathrm{P} 3$ and $\mathrm{P} 1 \mathrm{C} 2 \mathrm{P} 3$ obtained by substitution of $\mathrm{P} 1$ or $\mathrm{P} 2$ of Pch12 with the corresponding segment of $\mathrm{Chr} 3$ resulted in significantly reduced virulence and virus accumulation (Fig. 4B and C), indicating that RNA1 and RNA2 of Pch12 are important for Pch12 to maintain its strong virulence. Replacement of either RNA1 or RNA2 of Chr3 with that of Pch12 only did not remarkably increase virulence and virus titer (Fig. $4 \mathrm{~B}$ and $\mathrm{C}$ ), suggesting that RNA1 or RNA2 of Pch12 alone is not sufficient to enhance the pathogenicity of Chr3. Taken together, these data suggest that RNA1 and RNA2 codetermine the aggressive pathogenicity of Pch12.

\section{Both the 1C terminal sequence of RNA1 and the $2 \mathrm{M}$ region of RNA2 regions contain the pathogenic determinants of PNRSV.}

To delimit the regions in RNA1 and RNA2 that codetermine pathogenicity, chimeric viruses were constructed by swapping different regions in RNA1 or RNA2 of Pch12 with corresponding regions of $\mathrm{Chr} 3$. Assays of the resulting chimeric viruses were performed on cucumber seedlings to compare the pathogenicity of these chimeric viruses and Pch12. In brief, two hybrid viruses containing sequence replacement within RNA1, designated Pch12(C1N) and Pch12(C1C), were created by swapping of the $\mathrm{N}$ - and $\mathrm{C}$-terminal region of Pch12 RNA1 with that of Chr3 RNA1 (Fig. 5A). Pch12(C1C) exhibited 
reduced virulence and the virus accumulated to a level similar to $\mathrm{Chr} 3$, whereas the virulence of $\mathrm{Pch} 12(\mathrm{C} 1 \mathrm{~N})$ remained unchanged compared with Pch12 (Fig. 5B and C); therefore, the C-terminal region of Pch12 RNA1 should contain the pathogenic determinant. For RNA2, Pch12(C2C) and Pch12(C2N$2 \mathrm{M})$ were generated by replacement of the $\mathrm{C}$-terminal region of Pch12 RNA2 with that of Chr3 RNA2 and substitution of the 2N-2M region of Pch12 RNA2 with that of Chr3 RNA2, respectively (Fig. 5A). Pch12(C2C) did not significantly compromise its infectivity and virus accumulation but Pch12(C2N2M) did (Fig. 5B and C), suggesting that the pathogenic factor resides in the $2 \mathrm{~N}-2 \mathrm{M}$ region. To further map the pathogenic determinant in RNA2, the $2 \mathrm{~N}$ and $2 \mathrm{M}$ regions of Pch12 RNA2 were replaced with the corresponding region of Chr3 RNA2 to produce chimeric viruses $P \operatorname{ch} 12(\mathrm{C} 2 \mathrm{~N})$ and $\mathrm{Pch} 12(\mathrm{C} 2 \mathrm{M})$, respectively (Fig. 5A). Pch12(C2N) remained at a level of pathogenicity similar to Pch12, whereas Pch12(C2M) showed significantly reduced virulence and virus titer (Fig. 5B and C). Taken together, the above results suggest that the pathogenicity of PNRSV is conferred by the C-terminal region in RNA1 and the $2 \mathrm{M}$ region in $\mathrm{RNA} 2$.
Amino acid K279 in the RNA2-encoded P2 protein and the RNA1 C-terminal nucleotide sequence are pathogenic determinants of Pch12.

Because pathogenic determinants are often identified in protein sequences (Chowda-Reddy et al. 2011; Kang et al. 2012; Tian and Valkonen 2013), the amino acid sequences of RNA1encdoded P1 and RNA2-encoded P2 of Chr3 and Pch12, respectively, were pairwise aligned (Supplementary Fig. S1). Sequence alignments showed that the $\mathrm{P} 1$ protein differed in five of 1,044 amino acid residues between Chr3 and Pch12. Of these five amino acid residues, two (i.e., K/R at residue 753 and $\mathrm{L} / \mathrm{V}$ at 851$)(\mathrm{Pch} 12 / \mathrm{Chr} 3)$ were in the $1 \mathrm{C}$ region (the helicase domain). The P2 protein (RNA-dependent RNA polymerase [RdRp]) differed in 15 of 799 amino acids, and four of them $(\mathrm{G} / \mathrm{D}$ at $265, \mathrm{~K} / \mathrm{N}$ at $279, \mathrm{~L} / \mathrm{F}$ at 383 , and $\mathrm{A} / \mathrm{T}$ at 421$)$ (Pch12/Chr3), resided in the $2 \mathrm{M}$ region (Fig. 5).

To identify the key amino acid or acids in the $1 \mathrm{C}$ region, single or double amino acid substitutions (i.e., $\mathrm{K}$ to $\mathrm{R}$ at residue 753 or $\mathrm{L}$ to $\mathrm{V}$ at 851 or simultaneous mutations at these two residues) were introduced into the $1 \mathrm{C}$ protein of Pch12 RNA1 to generate mutants Pch12(P1-K753R), Pch12(P1-L851V),
A
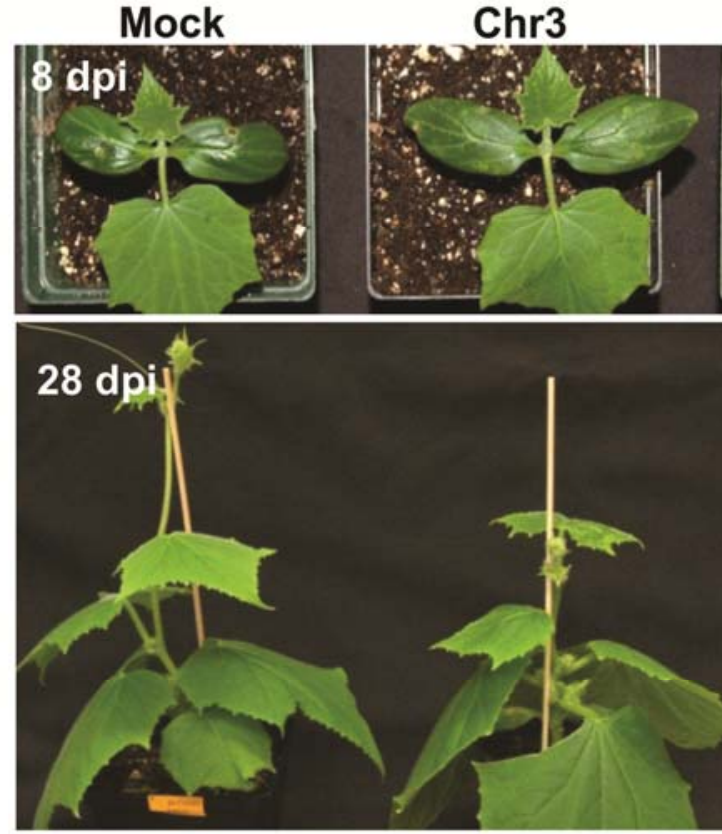

\section{Pch12}
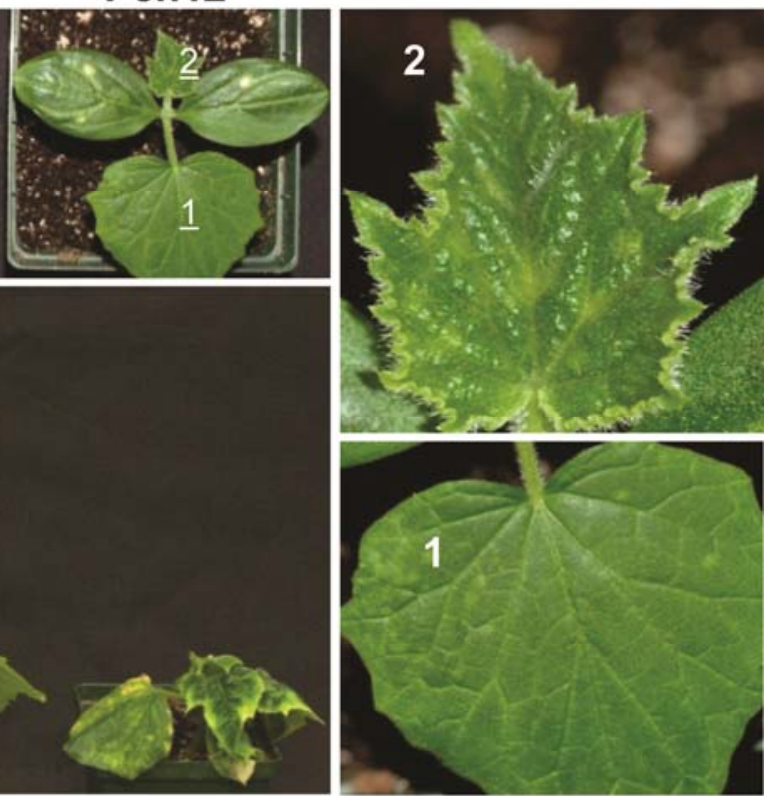

B

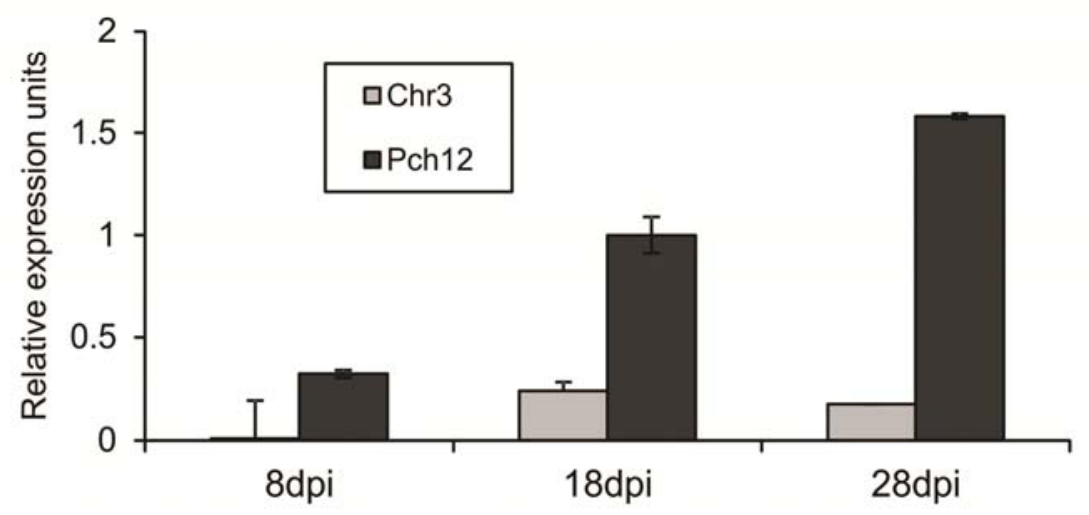

Fig. 3. Pathogenicity discrepancy of Prunus necrotic ringspot virus isolates Chr3 and Pch12 in Cucumis sativus 'Straight Eight'. A, Symptoms observed in Chr3- and Pch12-infected cucumber seedlings. All seedlings infected by Pch12 showed chlorotic and necrotic spots on the first and second true leaf at 8 days postinoculation (dpi), and stunted growth and extreme leaf distortion at 28 dpi. Chr3-infected seedlings did not show detectable symptoms at 8 dpi, and shorter stature (than mock-treated controls) was evident at 28 dpi. B, Detection of relative virus accumulation level in Chr3 and Pch12-infected cucumber seedlings using real-time quantitative polymerase chain reaction. Newly emerging leaves were sampled at 8 , 18 , and 28 dpi. Actin transcript levels were determined as internal controls. At least three independent experiments were carried out and, in each experiment, four cucumber seedlings were inoculated with Chr3, Pch12, and buffer (Mock), respectively. 

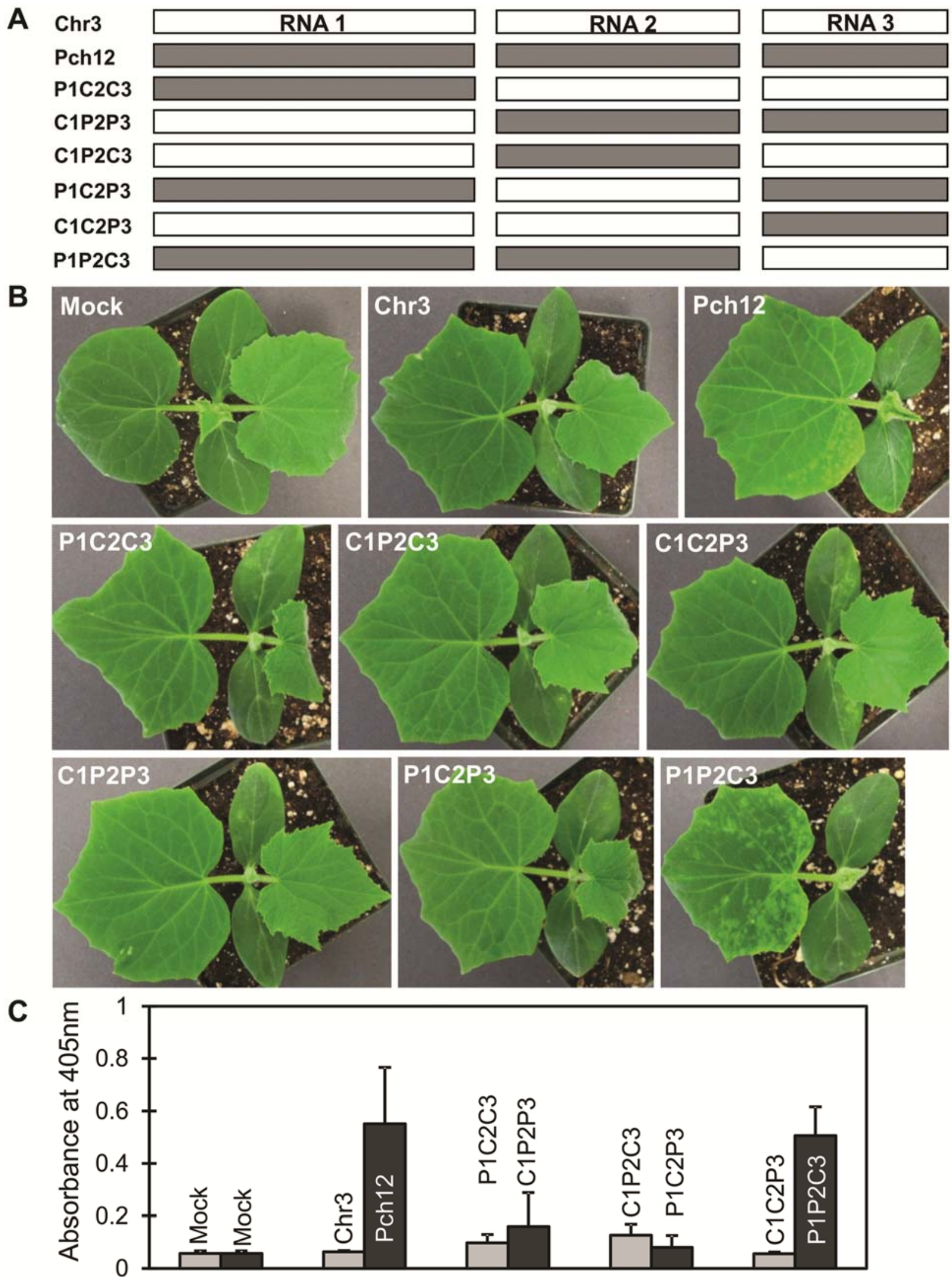

Fig. 4. Pathogenicity test of the reassorted viruses between Chr3 and Pch12 in Cucumis sativus 'Straight Eight'. A, Schematic diagram of the reassorted viruses obtained by swapping genomic segment RNA1, RNA2, or RNA3 between Chr3 and Pch12, and the resulting chimeras are designated as P1C2C3, C1P2P3, C1P2C3, P1C2P3, C1C2P3, and P1P2C3. White and gray boxes indicate Chr3- and Pch12-derived genomic segments RNA1, RNA2, and RNA3, respectively. B, Symptoms induced by the six reassorted viruses and wild-type Chr3 and Pch12. At 8 days postinoculation, the photographs were taken and the newly emerging leaves were sampled for the double-antibody sandwich enzyme-linked immunosorbent assay (DAS-ELISA) analysis. C, Accumulation level of Prunus necrotic ringspot virus in newly emerging leaves was detected by DAS-ELISA. Error bars denote standard errors of the mean. At least three independent experiments were carried out and, in each experiment, four cucumber seedlings were inoculated with Chr3, Pch12, each of the reassorted viruses, and buffer (Mock), respectively. 
A
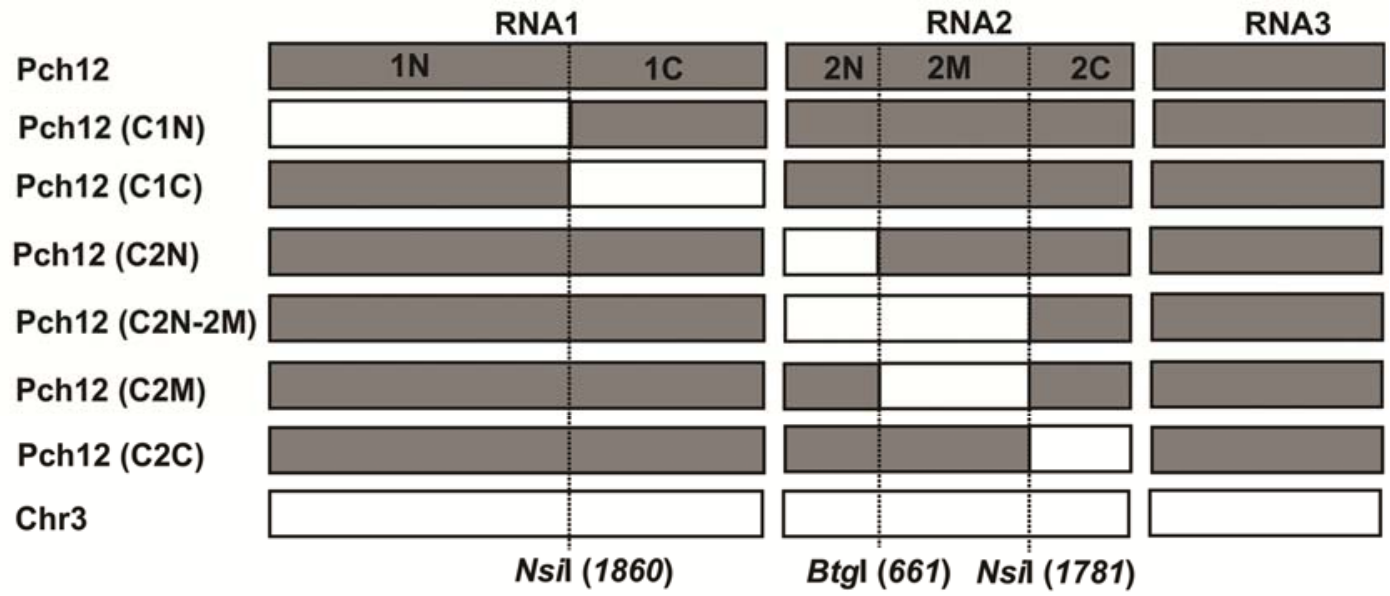

B
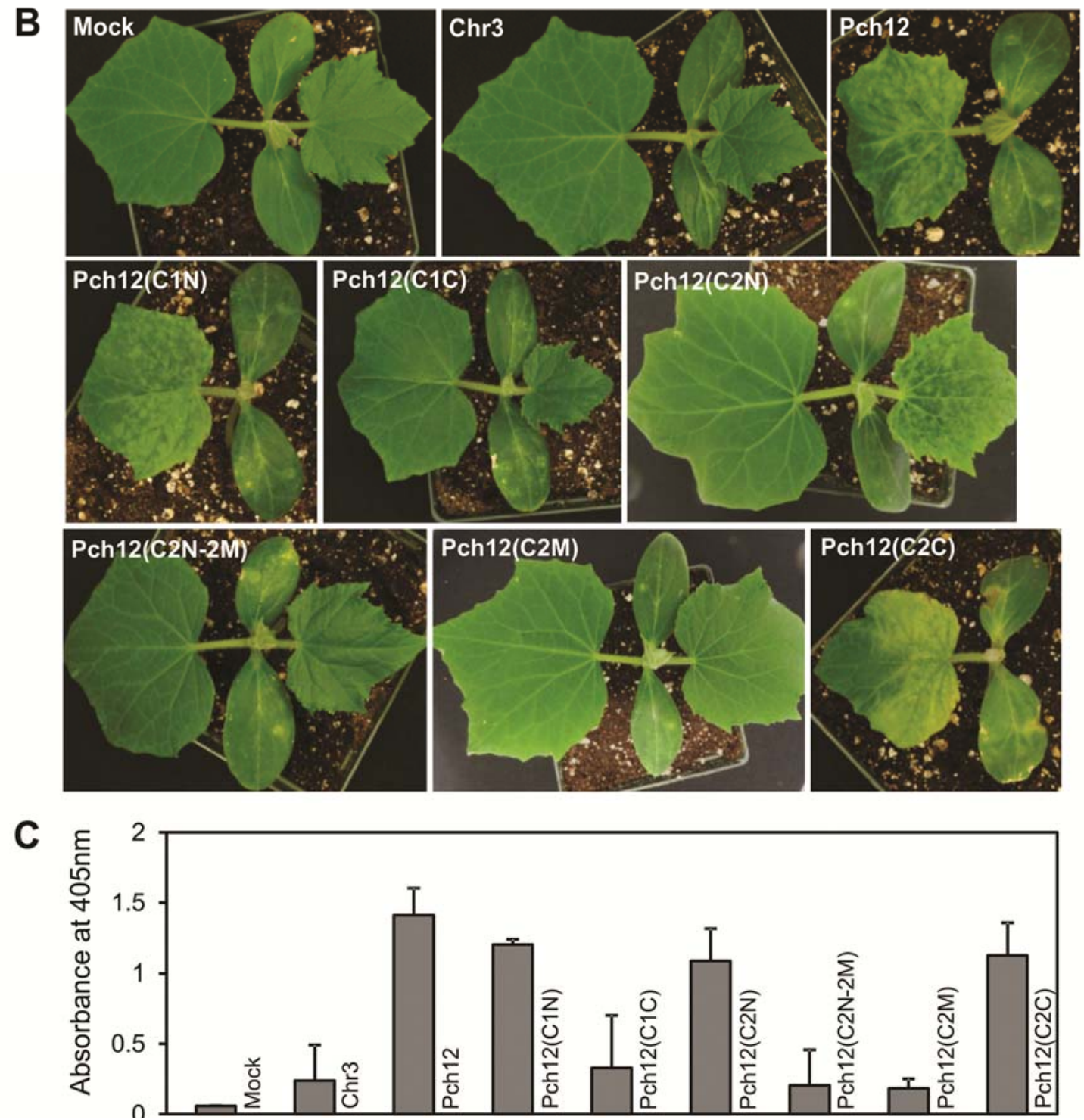

Fig. 5. Pathogenicity test of the hybrid viruses between Chr3 and Pch12 inCucumis sativus 'Straight Eight'. A, Schematic diagram of the hybrid viruses generated by replacing the different regions in RNA1 or RNA2 in Pch12 with the corresponding ones in Chr3. White and gray boxes indicate Chr3 and Pch12derived regions, respectively. Dotted lines show the exchange position, indicated by the common restriction site of Chr3 and Pch12. The obtained chimeric viruses are designated as Pch12(C1N), Pch12(C1C), Pch12(C2C), Pch12(C2N-2M), Pch12(C2N), and Pch12(C2M) B, Symptoms induced by the hybrid viruses and wild-type viruses $\mathrm{Chr} 3$ and Pch12. At 8 days postinoculation, the photographs were taken and the newly emerging leaves were sampled for the double-antibody sandwich enzyme-linked immunosorbent assay (DAS-ELISA) analysis. C, Accumulation level of Prunus necrotic ringspot virus in newly emerging leaves was detected via DAS-ELISA. Error bars denote standard errors of the mean. At least three independent experiments were carried out and, in each experiment, four cucumber seedlings were inoculated with Chr3, Pch12, each of the chimeric viruses, and buffer (Mock), respectively. 
and Pch12(P1-K753K, L851V) (Table 2). These mutants were subjected to a pathogenicity test on cucumber plants. To our surprise, all three mutants induced severe symptom phenotypes similar to their wild-type virus, Pch12 (Table 2; Supplementary Fig. S2). Therefore, the pathogenic determinant in 1C region is likely at the nucleotide level rather than at the amino acid level.

To examine the key amino acid or acids in the $2 \mathrm{M}$ region, four single amino acid substitution mutants-Pch12(P2G265D), Pch12(P2-K279N), Pch12(P2-L383F), and Pch12(P2A421T)-were generated (Table 2). Cucumber plants inoculated with the three mutants Pch12 (P2-G265D), Pch12(P2-L383F), and Pch12(P2-A421T) produced symptom phenotypes similar to those with the wild-type virus Pch12. However, mutant Pch12(P2-K279N) induced latent or mild symptom phenotypes, similar to those induced by $\mathrm{Chr} 3$ but different from those induced by Pch12 (Table 1). Therefore, in addition to the $1 \mathrm{C}$ nucleotide sequence, amino acid K279 in $\mathrm{P} 2$ is essential for Pch12 to confer severe pathogenicity on cucumber plants.

\section{The Chr3 mutant with replacement of the $1 \mathrm{C}$ region from Pch12 and N279K mutation} in the $\mathbf{P} 2$ protein gains severe pathogenicity on cucumber.

To test whether the $1 \mathrm{C}$ region of Pch12 RNA1 together with $\mathrm{N} 279 \mathrm{~K}$ mutation can confer a higher level of virulence to $\mathrm{Chr} 3$, the 1C region of Chr3 RNA1was replaced with that of Pch12 RNA1, and N279K mutation was introduced into the P2 protein to generate mutant $\mathrm{Chr} 3(\mathrm{P} 1 \mathrm{C}, \mathrm{C} 2-\mathrm{N} 279 \mathrm{~K})$. When this virus mutant was infiltrated into cucumber, severe symptoms

Table 2. Amino acid substitution mutants deriving from $\mathrm{P} 1$ and $\mathrm{P} 2$ proteins with $\mathrm{Pch} 12$ as the background and their pathogenicity test in Cucumis sativus 'Straight Eight' ${ }^{\text {a }}$

\begin{tabular}{|c|c|c|c|c|c|c|c|}
\hline \multirow[b]{3}{*}{ Viruses $^{c}$} & \multicolumn{6}{|c|}{ Amino acid difference ${ }^{b}$} & \multirow[b]{3}{*}{ Symptoms $^{\mathrm{d}}$} \\
\hline & \multicolumn{2}{|c|}{$\mathbf{P 1}$} & \multicolumn{4}{|c|}{$\mathbf{P 2}$} & \\
\hline & 753 & 851 & 265 & 279 & 383 & 421 & \\
\hline Pch12 & $\mathrm{K}$ & $\mathrm{L}$ & G & $\mathrm{K}$ & $\mathrm{L}$ & A & Severe \\
\hline Chr3 & $\mathrm{R}$ & $\mathrm{V}$ & $\mathrm{D}$ & $\mathrm{N}$ & $\mathrm{F}$ & $\mathrm{T}$ & Mild \\
\hline Pch12(P1-K753R) & $\mathrm{R}$ & $\mathrm{L}$ & $\mathrm{G}$ & $\mathrm{K}$ & $\mathrm{L}$ & A & Severe \\
\hline Pch12(P1-L851V) & $\mathrm{K}$ & $\mathrm{V}$ & $\mathrm{G}$ & $\mathrm{K}$ & $\mathrm{L}$ & A & Severe \\
\hline Pch12(P1-K753R, L851V) & $\mathrm{R}$ & $\mathrm{V}$ & G & $\mathrm{K}$ & $\mathrm{L}$ & A & Severe \\
\hline Pch12(P2-G265D) & $\mathrm{K}$ & $\mathrm{L}$ & $\mathrm{D}$ & $\mathrm{K}$ & $\mathrm{L}$ & A & Severe \\
\hline Pch12(P2-K279N) & $\mathrm{K}$ & $\mathrm{L}$ & G & $\mathrm{N}$ & $\mathrm{L}$ & A & Mild \\
\hline Pch12(P2-L383F) & $\mathrm{K}$ & $\mathrm{L}$ & G & $\mathrm{K}$ & $\mathrm{F}$ & A & Severe \\
\hline Pch12(P2-A421T) & $\mathrm{K}$ & $\mathrm{L}$ & G & $\mathrm{K}$ & $\mathrm{L}$ & $\mathrm{T}$ & Severe \\
\hline
\end{tabular}

${ }^{a}$ Symptoms were observed at 8 days postinoculation.

${ }^{\mathrm{b}}$ Positions of amino acid substitutions are indicated.

${ }^{\mathrm{c}}$ Names of wild type or mutant viruses.

d Severe or mild symptoms in C. sativus 'Straight Eight'.
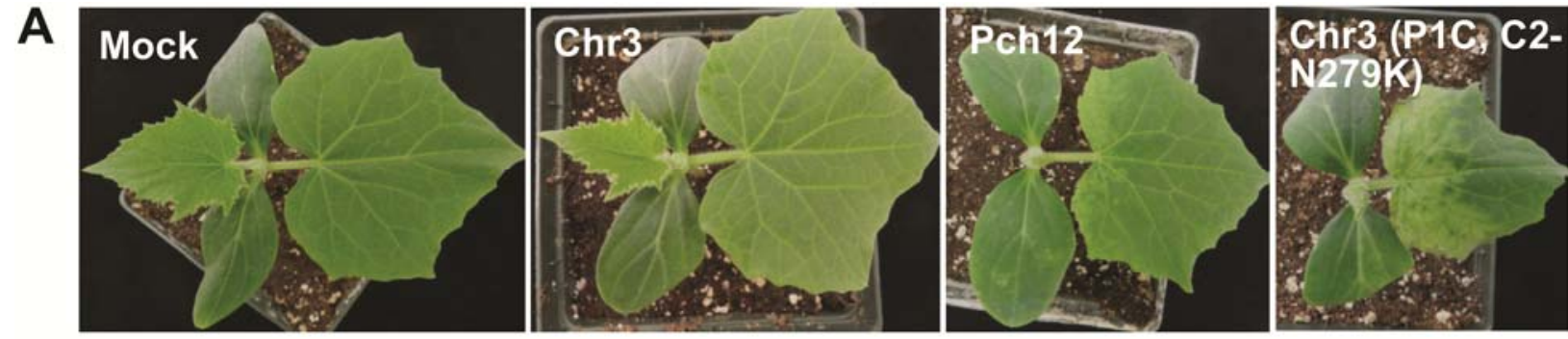

B

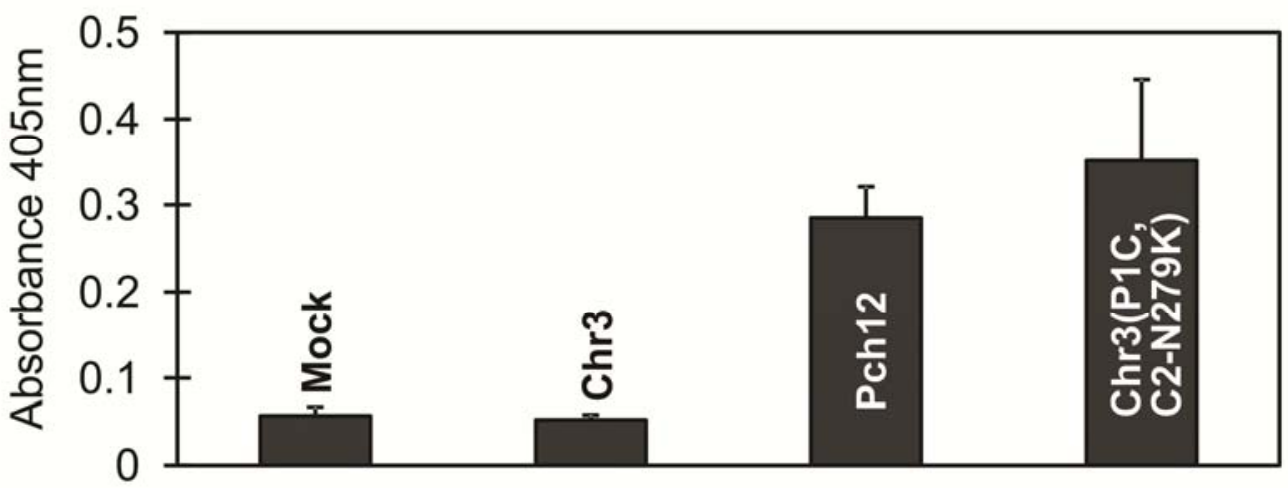

Fig. 6. Pathogenicity test of the chimeric virus Chr3(P1C, C2-N279K) in Cucumis sativus 'Straight Eight'. A, Symptoms in cucumber induced by Chr3(P1C, C2-N279K) that was generated by substitution of both the 1C region of RNA1 and N279 residue in P2 in Chr3 with the corresponding ones in Pch12. The chimeric virus $\mathrm{Chr} 3(\mathrm{P} 1 \mathrm{C}, \mathrm{C} 2-\mathrm{N} 279 \mathrm{~K}$ ) is much more aggressive than its wild-type virus $\mathrm{Chr}$. At 8 days postinoculation, the photographs were taken and the newly emerging leaves were sampled for double-antibody sandwich enzyme-linked immunosorbent assay (DAS-ELISA) analysis. B, Accumulation level of Prunus necrotic ringspot virus in newly emerging leaves was detected by DAS-ELISA. Error bars denote standard errors of the mean. At least three independent experiments were carried out and, in each experiment, four cucumber seedlings were inoculated with Chr3, Pch12, Chr3(P1C, C2-N279K), and buffer (Mock), respectively. 
such as necrosis, mosaic, and ringspot on the first true leaf were observed at 8 dpi (Fig. 6A), suggesting that this virus mutant gains severe virulence from Pch12. Moreover, DASELISA showed a much higher level of virus accumulation in plants infected by Chr3(P1C, C2-N279K) than by Chr3 (Fig. $6 \mathrm{~B})$. The titer of the mutant virus was similar to that of Pch12 (Fig. 6B). These results further suggest that the $1 \mathrm{C}$ region of RNA1 and amino acid $\mathrm{K}$ at residue 279 in the $\mathrm{P} 2$ protein of Pch12 are truly severe pathogenic determinants.

\section{Chr3 and Pch12 P2s are structurally different}

in the region containing residue 279 , and

the Chr3 P2 N279K mutant shares

high structural similarity with Pch12 P2.

As mentioned earlier, P2 is the RdRp of PNRSV. To compare the three-dimensional (3D) structures of Pch12- and Chr3-encoded $\mathrm{P} 2$ proteins and explore possible association between the localization of K279 in the RdRp and its functional role in pathogenicity, the LOMETS meta-threading server $(\mathrm{Wu}$ and Zhang 2007) was employed to predict the 3D structure of $\mathrm{P} 2$ proteins. The query sequence was threaded through a representative PDB structure library using LOMETS to identify the best possible template, and the model was built by MODELLER, aiming at constructing a 3D model close to the template (Roy et al. 2010; Sali and Blundell 1993). The template
'3ea5B', an importin subunit $\beta-1$ in Saccharomyces cerevisiae, was generated and ranked as the best template with a high confidence score (calculating based on a scoring function that takes into account the Z-score of the template, the confidence of the particular server, and the sequence identity between the query and the template) (Wu and Zhang 2007). Template 3 ea5B had a $92.6 \%$ coverage with the $\mathrm{P} 2$ proteins of $\mathrm{Chr} 3$ and Pch12. The 3D structure of P2 was U-like in shape and contained many $\alpha$-helices and loops but no $\beta$-sheets (Fig. 7A and B). Remarkably, N279 of Chr3 was located in the coil structure; however, K279 of Pch12 was positioned as the first residue of the $\alpha$-helix structure (from 279 to 292) (Fig. 7D and E). Comparison of the exposed surface of P2 in isolates Chr3 and Pch12 showed that N279 in Chr3 was completely exposed but $\mathrm{K} 279$ in Pch12 was nearly hidden (Fig. 7G and H). Interestingly, when the $\mathrm{N} 279 \mathrm{~K}$ mutation was introduced into the P2 protein of $\mathrm{Chr} 3$, the mutated amino acid drastically affected the 3D structure, and K279 of the Chr3(P2-N279K) mutant was also positioned as the first residue of $\alpha$-helix structure (from 279 to 292) and nearly hidden (Fig. 7F and I), highly similar to the corresponding local structure of Pch12 P2 (Fig. 7D and G). Therefore, the structural difference of K279 (Pch12) and N279 (Chr3) and the structural similarity of K279 (Pch12) and K279 in the mutant Chr3(P2-N289K) are well in agreement with their functional role in virulence.
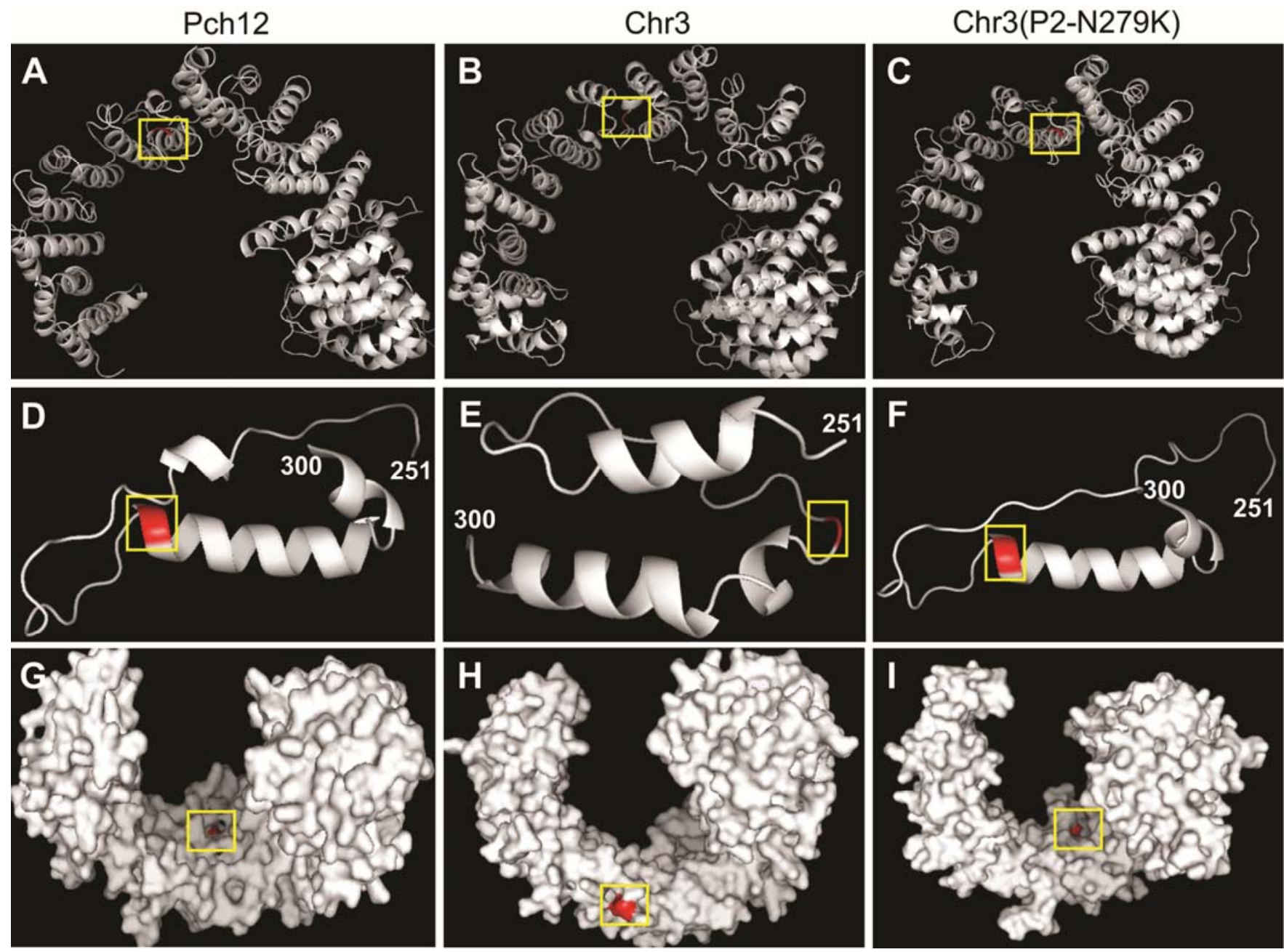

Fig. 7. Modeling of the $\mathrm{P} 2$ protein in Prunus necrotic ringspot virus isolates $\mathrm{Pch} 12$, Chr3, and Chr3(P2-N279K) using the LOMETS meta-threading server with '3ea5B' as a template. Cartoon diagram of the predicted structures of P2 is for A, Pch12; B, Chr3; and C, Chr3(P2-N279K) and D to F, the region approximately 251 to 300 of P2 is closely viewed underneath. Exposed surface structure of the P2 protein of G, Pch12; H, Chr3; and I, Chr3(P2-N279K). For the surface structure, N279 in Chr3 is completely exposed (H); however, K279 in Pch12 (G) or Chr3(P2-N279K) (I) is nearly hidden. N279 or K279 is shown in red and included by the yellow lined rectangle. 


\section{DISCUSSION}

Recently, we have surveyed PNRSV in the Niagara Fruit Belt in Canada. It was estimated that PNRSV occurred with an average incidence of $44.9 \%$ on cherry and peach trees (Cui et al. 2012a). All 31 Canadian isolates were classified into two groups: PV96 (including all 18 cherry isolates and 9 peach isolates) and PV32 (including 4 peach isolates). We completely sequenced cherry isolate Chr3 (PV96-type) and peach isolate Pch12 (PV32-type) (Cui et al. 2012b). In order to further study the relationship and pathogenicity of these two isolates, we constructed infectious full-length cDNA clones of $\mathrm{Chr} 3$ and Pch12. We show here that the full-length cDNA clones were infectious in the experimental host cucumber and their respective natural hosts cherry and peach. To our best knowledge, this was the first report of the successful construction of infectious cDNA clones of ilaviruses in fruit trees. The infectious cDNAs may serve as a powerful tool for molecular characterization of PNRSV replication and movement mechanisms, pathogenicity, and virus-host interactions.

In this study, we showed that both Chr3- and Pch12-derived clones were infectious on cucumber but Pch12 induced more severe symptoms than Chr3 (Fig. 2A), and the severe virulence was associated with high viral titer (Fig. 3B). Our data also support previous suggestions that isolates in the PV32 group tend to be more severe than those in the PV96 group (Hammond 2003). The PV96-type cherry isolate Chr3 was able to infect cherry with mild symptoms on systemic leaves but failed to infect peach (Fig. 2B; data not shown). The PV32-type peach isolate Pch12 was infectious in peach, with mild or undetectable symptoms on systemic leaves; but, in cherry, it induced severe necrosis on the systemic leaves and the death of the shoot tip (Fig. 2B to D), indicating that further viral spread was contained. Pch12 and Chr3 were obtained from the same orchard (Cui et al. 2012a) and they shared very high sequence identities (>98\% at the amino acid level) (Cui et al. 2012b). Therefore, they are closely related but have evolved to be adequately pathogenic to adapt to alternating Prunus hosts.

Using a hybrid virus approach by reassortment of RNA segments between Chr3 and Pch12, we found that swapping genomic segment RNA3 between Chr3 and Pch12 did not affect their pathogenicity in comparison with their respective wild-type viruses (Fig. 4). Instead, we demonstrated that both RNA1 and RNA2 contributed to the pathogenicity differences between Chr3 and Pch12 (Fig. 4). Therefore, the pathogenicity discrepancy of the two PNRSV isolates Chr3 and Pch12 is not determined by genomic RNA3 encoding the MP and CP. These two viral proteins and their gene sequences have been used in almost all publications for phylogenetic analysis of PNRSV (Aparicio and Pallás 2002; Aparicio et al. 1999; Cui et al. 2012a; Fiore et al. 2008; Glasa et al. 2002; Hammond 2003; Vasková et al. 2000). The results from this study suggest that RNA1 and RNA2 sequences might be more suitable for studying the correlation between viral pathogenicity and phylogroups than CP and MP genes. Because phylogenetic analysis of the RNA1 and RNA2 sequences was impossible due to the lack of sufficient PNRSV RNA1 and RNA2 sequences in the public domain, our suggestion remains to be tested in future studies. In the case of related viruses in the family Bromoviridae, it is well known that RNA1 or RNA2 are implicated to contain genetic determinants for virulence for Brome mosaic virus (BMV) (Ding et al. 2006) as well as for Cucumber mosaic virus (CMV) (Divéki et al. 2004; Karasawa et al. 1999; Kim and Palukaitis 1997; Lakshmanan and Gonsalves 1985).

Partial viral genome swapping followed by site-directed point mutagenesis for specific residues allowed us to conclude that amino acid K279 in the RNA2-encoded P2 protein is essen- tial for Pch12 to maintain severe virulence on cucumber (Table 2). As mentioned above, previous studies revealed several avirulence or virulence determinants in the RNA2-encoded P2 (RdRp) for some members of the family Bromoviridae. For instance, amino acid F631 in the P2 of CMV acts as the avirulence determinant via eliciting necrotic local lesions (Karasawa et al. 1999; Kim and Palukaitis 1997) whereas the amino acid at position 276 in P2 determines the symptom phenotypes in squash by controlling the rates of viral cell-to-cell movement in the inoculated cotyledons and the egress of the virus from the inoculated leaves (Choi et al. 2005). Because the C-terminal region of $\mathrm{P} 1$ and the $\mathrm{N}$-terminal region of $\mathrm{P} 2$ of Alfalfa mosaic virus or BMV could interact with each other and are involved in viral replication (Chen and Ahlquist 2000; van der Heijden et al. 2001), it is possible that PNRSV infection requires such an interaction and K279 may determine viral pathogenicity by mediating the P1-P2 interaction.

In this study, we also showed that the $1 \mathrm{C}$ region in RNA1 is required for Pch12 to confer severe virulence on cucumber (Fig. 5), and this region contains partial a coding region for P1 (including a partial hinge region between the methyltransferase and helicase domains and complete helicase domain) and $3^{\prime}$ untranslated region (UTR). In total, 16 nucleotides (including one in the $3^{\prime}$ UTR) and two amino acids are different in the $1 \mathrm{C}$ region between Chr3 and Pch12. Recently, Kang and associates (2012) have reported that the helicase domain encoded by CMV-P1 RNA1 determines susceptibility to systemic infection in 'Bukang' pepper, and four amino acid residues in this domain have been implicated as the determinant to maintain the systemic infection in Bukang. Different from this, single or double amino acid substitution mutants Pch12(P1-K753R), Pch12(P1-L851V), and Pch12 (P1-K753R, L851V) induced severe symptoms similar to the wild-type virus Pch12, demonstrating that the pathogenicity discrepancy between Chr3 and Pch12 does not result from the amino acid difference in the helicase domain. Consequently, we speculate that it is the nucleotide sequence rather than the amino acid sequence in the $1 \mathrm{C}$ region that determines the pathogenicity divergence of $\mathrm{Chr} 3$ and Pch12. We further looked into the nucleotide sequence in the $1 \mathrm{C}$ region and were particularly interested in a nucleotide in the $3^{\prime}$ UTR (e.g., T/C3248 [Pch12/Chr3]). It has been reported that the $3^{\prime}$ UTR of alfamo- and ilaviruses folds into a linear array of several stem-loops flanked by nonpaired sequences (including several conserved AUGC sequences), which may represent specific binding sites for the $\mathrm{CP}$ for the invading virus to initiate infection (Ansel-McKinney and Gehrke 1998; Aparicio et al. 2003; Bol 2005; Jaspars 1999; Neeleman et al. 2001; Reusken and Bol 1996). To examine the importance of the nucleotide T3248 in the pathogenicity of Pch12, a point mutant Pch12(RNA1-T3248C) was constructed and tested on cucumber. This mutant retained the same severe pathogenicity as the wide-type virus Pch12 (data not shown). These data suggest that T3248, if involved in pathogenicity, must function with other nucleotides. Future experiments will be designed to examine the role of the 16 different nucleotides of the $1 \mathrm{C}$ region in pathogenicity.

In summary, our data show that RNA1 and RNA2 of Chr3 and Pch12 codetermine viral pathogenicity to adapt to alternating hosts. The nucleotide sequences of the $1 \mathrm{C}$ region of RNA1 and amino acid K279 in RNA2-encoded P2 are the genetic determinants for the severe virulence of the PV32-type isolate Pch12. Introduction of the $1 \mathrm{C}$ region of Pch12 and K279 into the corresponding region or site of the less virulent PV96-type isolate $\mathrm{Chr} 3$ conferred the $\mathrm{Chr} 3$ mutant severe virulence (Fig. 6). Because reassorted viruses $\mathrm{P} 1 \mathrm{C} 2 \mathrm{C} 3$ and $\mathrm{C} 1 \mathrm{P} 2 \mathrm{C} 3$ remained as virulent as $\mathrm{Chr} 3$ (Fig. 4), the 1C nucleotide sequence or the K279-mediated structure of P2 (Fig. 7) alone is not sufficient 
to confer severe virulence. Therefore, they must act together to serve as a pathogenic determinant. It is reasonable to speculate that the severe virulence of Pch12 may be achieved through an interaction of P2 (with K279-mediated optimal structure) with the $1 \mathrm{C}$ region that controls RNA1 transcription and further modulates virus accumulation. Discovery of the molecular mechanism underlying the pathogenicity difference between Pch12 and Chr3 may rely on in-depth unraveling of RNA1 and P2 interactions, which is a critical area for future studies.

\section{MATERIALS AND METHODS}

\section{Virus isolates and plant materials.}

cDNA clones derived from two recently identified Canadian PNRSV isolates-Chr3 from cherry (PV96-type) and Pch12 from peach (PV32-type) (Cui et al. 2012b) -were used to construct the full-length cDNA infectious clones.

The experimental host cucumber (Cucumis sativus 'Straight Eight') and two PNRSV natural hosts, peach Prunus persica 'GF305' and 'Loring') and cherry ( $P$. avium 'Bing'), were used for the pathogenicity test. All cucumber seedlings were maintained in a growth chamber set to $16 \mathrm{~h}$ of light at $25^{\circ} \mathrm{C}$ and $8 \mathrm{~h}$ of darkness at $20^{\circ} \mathrm{C}$. 'GF305' peach plantlets were generated from in vitro multiplication using the following protocol. In brief, peach branches with unopened leaf buds were collected in early spring, and the leaf buds were cut from the branches and sterilized with $70 \%$ ethanol and $15 \%$ commercial bleach Javex, then rinsed with sterile water. Using 24-well plates, each sterilized leaf bud was placed in a paper plug wetted with liquid culture medium (Quoirin and Lepoivre [QL] + benzyladenine $(\mathrm{BA})_{0.2 \mathrm{mg} / \mathrm{liter}}+$ fructose $_{10 \mathrm{~g} / \mathrm{iter}}+$ glucose $\left._{5 \mathrm{~g} / \mathrm{iter}}\right)$ ). After 2 weeks of culture, the unfolded leaf buds were transferred to solid medium for further proliferation $\left(\mathrm{QL}+\mathrm{BA}_{1 \mathrm{mg} / \mathrm{iter}}+\right.$ fructose $_{10 \mathrm{~g} / \text { liter }}+$ glucose $_{5 / \text { gliter }}+$ ferulic acid $\left._{1 \mathrm{mg} / \text { liter }}\right)$. Young shoots were transferred to rooting medium $(1 / 2 \mathrm{QL}+$ indole butryric acid (IBA) $)_{3 \mathrm{mg} / \mathrm{iter}}+$ sucrose $_{10 \mathrm{~g} / \mathrm{liter}}$ ) for 4 days and then transferred to solid medium $\left(1 / 2 \mathrm{QL}+\right.$ sucrose $\left._{10 \mathrm{~g} / \mathrm{iter}}\right)$ for growth before transplanting into soil pots in a greenhouse.

'Loring' peach and 'Bing' cherry seedlings were obtained according to the following protocol. Cold-treated pits (at $4^{\circ} \mathrm{C}$ in darkness for 2 months for breaking dormancy) were cracked with a nutcracker to remove shells. Shell-free seed were sterilized with $70 \%$ ethanol and $20 \%$ commercial bleach Javex, then rinsed with sterile water. The surface-sterilized seed were soaked in sterile water for 2 to 3 days for the removal of the seed coat. The seed without the test were cultured on germination medium $\left(1 / 2 \mathrm{QL}+\right.$ fructose $_{10 \mathrm{~g} / \text { liter }}, \mathrm{pH}$ = 5.7). After approximately 2 to 3 weeks, the rooted seedlings were transplanted into soil pots. All cherry and peach plants were maintained in a growth cabinet in a regime of $16 \mathrm{~h}$ of light at $22^{\circ} \mathrm{C}$ and $8 \mathrm{~h}$ of darkness at $18^{\circ} \mathrm{C}$.

\section{Construction of infectious cDNAs clones of two PNRSV isolates Chr3 and Pch12.}

A binary plant expression vector, pCass4-Rz (Annamalai and Rao 2005), was used as the backbone plasmid to integrate full-length genomic cDNAs of PNRSV. The construction procedures were essentially as described by Annamalai and Rao (2005). Briefly, full-length cDNA sequences corresponding to the three genomic RNAs were amplified by PCR with the primer sets indicated (Supplementary Table S1). All of the PCR reactions were carried out using Phusion High-Fidelity DNA Polymerase (New England Biolabs, Pickering, ON, Canada). The resulting PCR products were digested with PstI, treated with T4 DNA polymerase to create blunt-ended products, followed by digestion with either $K p n I$ (for RNA1 and RNA2 ) or BamHI (for RNA3), and finally cloned into the corresponding sites $(S t u \mathrm{I} / K p n \mathrm{I}$ or $S t u \mathrm{I} /$ Bam $\mathrm{HI})$ of the pCass4-Rz vector. The inserted cDNAs were confirmed by DNA sequencing.

\section{Construction of partial genomic cDNA of RNA1 or RNA2 swapping constructs between Chr3 and Pch12.}

To assess the genomic regions of RNA1 and RNA2 on pathological properties, two RNA1 hybrids and four RNA2 hybrids were created using Pch12 as the background. First, sequence analysis revealed the presence of an NsiI site in the cDNA sequence of RNA1 at 1,860 or RNA2 at 1,781, and also in the pCass $4-\mathrm{Rz}$ vector at 6,557. By utilizing the NsiI sites to swap a partial T-DNA construct of RNA1 or RNA2 between Chr3 and Pch12, the hybrid viruses Pch12(C1N), Pch12(C1C), Pch12(C2C), and Pch12(C2N-2M) were created. Second, for the convenience of construction, the DNA fragment containing the double $35 \mathrm{~S}$ promoter and the full-length cDNA of RNA2 of Chr3 or Pch12 was taken out by HindIII/KpnI digestion from the infectious cDNA construct, and cloned into the PUC18 vector. By utilizing HindIII/BtgI and BtgI/NsiI sites to swap $2 \mathrm{~N}$ and $2 \mathrm{M}$ regions, respectively, the hybrid cDNAs of RNA2 were obtained (Fig. 5A). Then, the hybrid cDNA of RNA2 and its preceding double $35 \mathrm{~S}$ promoter was taken out by HindIII/KpnI digestion, and inserted back into the HindIII/KpnI-treated pCass4-Rz vector. Thus, the hybrid virus Pch12(C2N) and Pch12(C2M) were created.

\section{Site-directed mutagenesis.}

For the convenience of mutagenesis, the DNA fragment containing the double $35 \mathrm{~S}$ promoter and the full-length cDNA of RNA1 or RNA2 of Pch12 was taken out by HindIII/KpnI digestion from the infectious cDNA constructs and cloned into the PUC18 vector. The resulting clones were served as templates to introduce single and double mutations using a QuickChange II XL Site-Directed Mutagenesis kit (catalog number 200522; Stratagene, La Jolla, CA, U.S.A.) following the supplier's instructions. The $1 \mathrm{C}$ or $2 \mathrm{M}$ region of Pch12 containing the desired mutations was inserted back into the HindIII/KpnI sites of the pCass4-Rz vector. All mutations were confirmed by DNA sequencing.

\section{Agroinfiltration.}

Seedlings of $C$. sativus 'Straight Eight' with fully expanded cotyledons were used for Agrobacterium-mediated transient expression. Briefly, three types of binary vectors (RNA1, RNA2, and RNA3), including their corresponding partial genome-swapping hybrids and point mutants, were transformed into Agrobacterium tumefaciens GV3101 via electroporation. Agrobacteria were grown overnight in Luria-Bertani medium containing kanamycin at $100 \mu \mathrm{g} \mathrm{ml}^{-1}$ and rifampicin at $20 \mu \mathrm{g}$ $\mathrm{ml}^{-1}$. The agrobacterial cells were harvested by centrifugation, and then resuspended in infiltration buffer $\left(10 \mathrm{mM} \mathrm{MgCl}_{2}, 10\right.$ $\mathrm{mM}$ MES, and $150 \mu \mathrm{M}$ acetosyringone). After incubation for 2 $\mathrm{h}$ at room temperature, the culture was diluted to an optical density at $600 \mathrm{~nm}$ of 1.0. Three Agrobacterium cultures were mixed with equal volume, and $150 \mu \mathrm{l}$ of the mixed cultures were infiltrated into two cotyledons of 'Straight Eight' seedlings from the abaxial surface. For each mixed culture, four cucumber seedlings were used. At least three biological replicates were conducted.

\section{Biolistic bombardment.}

$P$. avium 'Bing' and $P$. persica 'Loring' and 'GF305' plants (approximately 3 to 4 weeks old and approximately 10 to 15 $\mathrm{cm}$ in height) were biolistically inoculated using the Helios Gene Gun System (Bio-Rad, Hercules, CA, U.S.A.). Microcarrier cartridges were prepared with $1.0 \mu \mathrm{m}$ gold particles coated with the equally mixed plasmids at a DNA loading ratio 
of $6 \mu \mathrm{g} / \mathrm{mg}$ of gold and a microcarrier loading quantity of 0.5 $\mathrm{mg} /$ shooting, according to the manufacturer's instructions. Helium pressures of 200 psi were used. Three cartridges were shot onto different leaves of the same plant from the leaf adaxial side. For each plasmid mix, 4 to 6 peach or cherry seedlings were bombarded per experiment, and at least three biological replicates were performed.

DAS-ELISA, RT-PCR, and real-time quantitative RT-PCR. After agroinfiltration or biolistic bombardment, PNRSV in the treated plants was detected by DAS-ELISA, RT-PCR, or real-time quantitative (q)RT-PCR at the days indicated. To quantity virus accumulation level of wild-type or hybrid viruses by the DAS-ELISA method, a Bradford assay was employed to equal the loading total proteins in crude extract, then DASELISA was conducted with an ELISA kit (catalog number PSA 30500; Agdia, Elkhart, IN, U.S.A.) following the manufacturer's protocol. For RT-PCR and real-time qRT-PCR, total RNAs were extracted from newly emerging leaves using TRIzol (Invitrogen, Burlington, ON, Canada) and treated with DNase I. The first-strand cDNAs were generated by reverse-transcription reactions with random hexamer primers (New England Biolabs) and SuperScript III Reverse Transcriptase (Invitrogen). RT-PCR was carried out to amplify the full-length $\mathrm{CP}$ gene using the primer set MG1/MG2 (Glasa et al. 2002), essentially as described (Cui et al. 2012a). Real-time qPCR was performed and analyzed with the CFX96 Real-Time PCR Detection System (Bio-Rad) following the manufacturer's instructions. The expression of the CP gene of PNRSV was detected by the realtime qPCR to reflect virus accumulation level and expression of the actin gene (accession number AB698859) was used as an internal control to normalize the data.

\section{Modeling of the 3D structures of the $\mathrm{P} 2$ protein of $\mathrm{Chr} 3$ and $\mathrm{Pch} 12$}

Modeling of 3D structures of P2 of PNRSV isolates Chr3 and Pch12 was carried out using web server Local Meta-Threading Server (LOMETS) (Wu and Zhang 2007), which builds fulllength models by MODELLER aiming at constructing a 3D model close to the template (Roy et al. 2010; Sali and Blundell 1993). The structures were constructed using PyMol.

\section{ACKNOWLEDGMENTS}

H. Cui was a recipient of a scholarship from the China Scholarship Council. This work was supported, in part, by an Agriculture and Agri-Food Canada (AAFC) PPV grant and an NSERC Discovery Grant to A. Wang. We thank A. L. N. Rao (University of California at Riverside) for the generous gift of plasmid pCass4-Rz, P. Abbasi (AAFC) for cucumber seed, H. Wang (AAFC) for providing peach and cherry seedlings, A. Molnar (AAFC) for photography, and J. McNeil (AAFC) for technical assistance.

\section{LITERATURE CITED}

Annamalai, P., and Rao, A. L. N. 2005. Replication-independent expression of genome components and capsid protein of brome mosaic virus in planta: A functional role for viral replicase in RNA packaging. Virology 338:96-111.

Ansel-Mckinney, P., and Gehrke, L. 1998. RNA determinants of a specific RNA-coat protein peptide interaction in alfalfa mosaic virus: Conservation of homologous features in ilarvirus RNAs. J. Mol. Biol. 278:767785 .

Aparicio, F., and Pallás, V. 2002. The molecular variability analysis of the RNA 3 of fifteen isolates of Prunus necrotic ringspot virus sheds light on the minimal requirements for the synthesis of its subgenomic RNA. Virus Genes 25:75-84.

Aparicio, F., Myrta, A., Di Terlizzi, B., and Pallás, V. 1999. Molecular variability among isolates of Prunus necrotic ringspot virus from different Prunus spp. Phytopathology 89:991-999.

Aparicio, F., Vilar, M., Perez-Payá, E., and Pallás, V. 2003. The coat pro- tein of Prunus necrotic ringspot virus specifically binds to and regulates the conformation of its genomic RNA. Virology 313:213-223.

Bol, J. F. 2005. Replication of alfamo- and ilarviruses: Role of the coat protein. Annu. Rev. Phytopathol. 43:39-62.

Chen, J., and Ahlquist, P. 2000. Brome mosaic virus polymerase-like protein $2 \mathrm{a}$ is directed to the endoplasmic reticulum by helicase-like viral protein 1a. J. Virol. 74:4310-4318.

Choi, S. K., Palukaitis, P., Min, B. E., Lee, M. Y., Choi, J. K., Ryu, K. H. 2005. Cucumber mosaic virus 2 a polymerase and 3 a movement proteins independently affect both virus movement and the timing of symptom development in zucchini squash. J. Gen. Virol. 86:1213-1222.

Chowda-Reddy, R.V., Sun, H., Chen, H., Poysa, V., Ling, H., Gijzen, M., and Wang, A. 2011. Mutations in the P3 protein of Soybean mosaic virus G2 isolates determine virulence on Rsv4-genotype soybean. Mol. PlantMicrobe Interact. 24:37-43.

Cui, H., Hong, N., Wang, G., and Wang, A. 2012a. Detection and genetic diversity of Prunus necrotic ringspot virus in the Niagara Fruit Belt, Canada. Can. J. Plant Pathol. 34:104-113.

Cui, H., Hong, N., Wang, G., and Wang, A. 2012b. Molecular characterization of two Prunus necrotic ringspot virus isolates from Canada. Arch. Virol. 157:999-1001.

Ding, X. S., Schneider, W. L., Chaluvadi, S. R., Rouf Mian, M. A., and Nelson, R. S. 2006. Characterization of a Brome mosaic virus strain and its use as a vector for gene silencing in monocotyledonous hosts. Mol. Plant-Microbe Interact. 19:1229-1239.

Divéki, Z., Salánki, K., and Balázs, E. 2004. The necrotic pathotype of the Cucumber mosaic virus (CMV) Ns strain is solely determined by amino acid 461 of the 1a protein. Mol. Plant-Microbe Interact. 17:837-845.

Fauquet, C. M., Mayo, M. A., Maniloff, J., Desselberger, U., and Ball, L. A., eds. 2005. Virus Taxonomy, Eighth Report of the International Committee on Taxonomy of Viruses. Elsevier Academic Press, San Diego, CA, U.S.A.

Fiore, N., Fajardo, T. V. M, Prodan, S., Herranz, M. C., Aparicio, F., Montealegre, J., Elena, S. F., Pallás, V., and Sánchez-Navarro, J. 2008 Genetic diversity of the movement and coat protein genes of South American isolates of Prunus necrotic ringspot virus. Arch. Virol. 153:909-919.

Francki, R. I. B. 1985. The viruses and their taxonomy. Pages 1-19 in: The Plant Viruses. Vol. 1, Polyhedral Virions with Tripartite Genomes. R. I. B. Francki, ed. Plenum Press, New York.

Glasa, M., Betinová, E., Kúdela, O., and Šubr, Z. 2002. Biological and molecular characterisation of Prunus necrotic ringspot virus isolates and possible approaches to their phylogenetic typing. Ann. Appl. Biol. 140:279-283

Hammond, R. W. 2003. Phylogeny of isolates of Prunus necrotic ringspot virus from the Ilarvirus ringtest and identification of group-specific features. Arch. Virol. 148:1195-1210.

Hammond, R. W, and Crosslin, J. M. 1998. Virulence and molecular polymorphism of Prunus necrotic ringspot virus isolates. J. Gen. Virol. 79:1815-1823.

Herranz, M. C, Sanchez-Navarro, J. A., Aparicio, F., and Pallás, V. 2005. Simultaneous detection of six stone fruit viruses by non-isotopic molecular hybridization using a unique riboprobe or 'polyprobe'. J. Virol. Methods 124:49-55.

Jaspars, E. M. J. 1999. Genome activation in alfamo- and ilarviruses. Arch. Virol. 144:843-863.

Jridi, C., Martin, J. F, Marie-Jeanne, V., Labonne, G., and Blanc, S. 2006 Distinct viral populations differentiate and evolve independently in a single perennial host plant. J. Virol. 80:2349-2357.

Kang, W. H., Seo, J. K, Chung, B. N., Kim, K. H., and Kang, B. C. 2012 Helicase domain encoded by Cucumber mosaic virus RNA1 determines systemic infection of Cmrl in pepper. PLoS ONE 7:e43136.

Karasawa, A., Okada, I., Akashi, K., Chida, Y., Hase, S., Nakazawa-Nasu, Y., Ito, A., and Ehara, Y. 1999. One amino acid change in Cucumber mosaic virus RNA polymerase determines virulent/avirulent phenotypes on cowpea. Phytopathology 89:1186-1192.

Kim, C. H., and Palukaitis, P. 1997. The plant defense response to Cucumber mosaic virus in cowpea is elicited by the viral polymerase gene and affects virus accumulation in single cells. EMBO (Eur. Mol. Biol. Organ.) J. 16:4060-4068

Lakshmanan, D. K., and Gonsalves, D. 1985. Genetic analyses of two large-lesion isolates of Cucumber mosaic virus. Phytopathology 75:758-762.

Neeleman, L., Olsthoorn, R. C. L, Linthorst, H. J. M, and Bol, J. F. 2001. Translation of a nonpolyadenylated viral RNA is enhanced by binding of viral coat protein or polyadenylation of the RNA. Proc. Natl. Acad. Sci. U.S.A. 98:14286-14291.

Oliver, J. E., Freer, J., Andersen, R. L., Cox, K. D., Robinson, T. L., and Fuchs, M. 2009. Genetic diversity of Prunus necrotic ringspot virus isolates within a cherry orchard in New York. Plant Dis. 93:599-606. 
Pallas, V., Aparicio, F., Herranz, M. C., Amari, K., Sanchez-Pina, M. A., Myrta, A., and Sanchez-Navarro, J. A. 2012. Ilarviruses of Prunus spp.: A continued concern for fruit trees. Phytopathology 102:11081120.

Peiró, A., Pallás, V., and Sánchez-Navarro, J. A. 2012. Simultaneous detection of eight viruses and two viroids affecting stone fruit trees by using a unique polyprobe. Eur. J. Plant Pathol. 132:469-475.

Reusken, C. B. E. M., and Bol, J. F. 1996. Structural elements of the 3'terminal coat protein binding site in alfalfa mosaic virus RNAs. Nucleic Acids Res. 24:2660-2665.

Roy, A., Kucukural, A., and Zhang, Y. 2010. I-TASSER: A unified platform for automated protein structure and function prediction. Nat. Prot. 5:725-738.

Saade, M., Aparicio, F., Sanchez-Navarro, J. A., Herranz, M. C., Myrta, A., Di Terlizzi, B., and Pallas, V. 2000. Simultaneous detection of the three ilarviruses affecting stone fruit trees by nonisotopic molecular hybridization and multiplex reverse-transcription polymerase chain reaction. Phytopathology 90:1330-1336.

Sali, A., and Blundell, T. L. 1993. Comparative protein modelling by satisfaction of spatial restraints. J. Mol. Biol. 234:779-815.

Sánchez-Navarro, J. A., and Pallás, V. 1997. Evolutionary relationships in the ilarviruses: Nucleotide sequence of Prunus necrotic ringspot virus RNA 3. Arch. Virol. 142:749-763.
Sánchez-Navarro, J. A., Aparicio, F., Herranz, M. C., Minafra, A., Myrta, A., and Pallás, V. 2005. Simultaneous detection and identification of eight stone fruit viruses by one-step RT-PCR. Eur. J. Plant Pathol. 111:77-84.

Tian, Y.-P., and Valkonen, J. P. T. Genetic determinants of Potato virus $Y$ required to overcome or trigger hypersensitive resistance to PVY strain group O controlled by the gene $\mathrm{Ny}$ in potato. Mol. Plant-Microbe Interact. 26:297-305.

van der Heijden, M. W., Carette, J. E, Reinhoud, P. J, Haegi, A., and Bol, J. F. 2001. Alfalfa mosaic virus replicase proteins P1 and P2 interact and colocalize at the vacuolar membrane. J. Virol. 75:1879-1887.

Vašková, D., Petrzik, K., and Karešová, R. 2000. Variability and molecular typing of the woody-tree infecting Prunus necrotic ringspot ilarvirus. Arch. Virol. 145:699-709.

Wu, S., and Zhang, Y. 2007. LOMETS: A local meta-threading-server for protein structure prediction. Nucleic Acids Res. 35:3375-3382.

\section{AUTHOR-RECOMMENDED INTERNET RESOURCES}

LOMETS (Local Meta-Threading-Server): zhanglab.ccmb.med.umich.edu/LOMETS

PyMol database: www.pymol.org 